\title{
6 Blind Men, an Elephant, and the Peer-Review Process
}

DOI: $10.3766 /$ jaaa.29.10.1

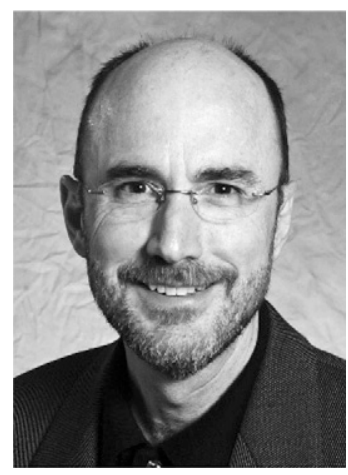

$\mathrm{T}$ he JAAA will turn 30 years of age this coming year as we put to bed the November/December issue of volume 29. Neither the Journal nor the Academy itself would exist were it not for Dr. James Jerger who is the Academy's first President and the Journals' first Editor-in-Chief. It is certainly noteworthy that Dr. Jerger will celebrate his $90^{\text {th }}$ birthday this coming year. We wish him all the best.

I have had the good fortune to serve as the editor of the American Journal of Audiology (AJA) and then with Dr. Devin McCaslin as the editor of the Journal of the American Academy of Audiology (JAAA). Editors are afforded the luxury of being able to see new data before anyone else. Before becoming an editor I began my career as an author. For my editorial this month I wanted to discuss the topic of the peer-review process which is the life-blood of the journal. I wanted to describe the process from the vantage point of the author, the reviewer, and the editor.

As an author I encountered all of the frustrations of a young and inexperienced writer. We all begin our careers as authors. It is common for the first efforts of new writers to be unsuccessful. This can be mitigated somewhat if the new writer can find a mentor to help them craft the story that is their research project. The most difficult aspect of being unsuccessful is the tendency for the young author to take personally the rejection of their article. Often a rejection is accompanied by detailed reviews. These represent efforts by the referees to coach the writer on how to improve their manuscript so that it might find life in another journal venue.

My advice is to interpret even the harshest reviews as opportunities to improve your next submission. A second word of advice is to view anything short of an outright rejection as a "conditional acceptance." So much of the success in publishing depends on persistence. It might take weeks or months to revise a manuscript in keeping with the reviewers' comments however my observation has been that those authors are eventually successful in their efforts to be published.

A third word of advice is to contact the editor of a journal you read regularly and volunteer your services as a reviewer. Shortly following my first few publications I began to be contacted by journal editors requesting my assistance in reviewing manuscripts. Returning reviews before the deadline ensured I would receive additional manuscripts. There is no better way to understand the peer-review process than to "stand in the shoes" of the reviewer. As a reviewer you learn quickly that it is your responsibility to identify not only the virtues but also all of the short-comings of the paper you have been assigned. All at once you see clearly that the reviewers of your work were simply doing the job assigned to them by the journal editor. Being a reviewer makes you more critical of your own work, and, in turn, makes it more likely you will be successful.

Lastly, there are few editorships available in our profession. I have had the honor of serving as an editor of JAAA for the past 5-6 years. The editor views the peerreview process from yet another vantage point. In addition to making certain the review process is fair, the editor has to ensure that there is sufficient content to fill, in the case the JAAA, 10 issues of the journal each year. This can be challenging when content decreases or when the quality of the submitted manuscripts is poor.

So, much like the parable of the 6 blind men and the elephant, the peer-review process looks very different depending on the vantage point from where it is perceived, from the perspective of the author, the reviewer, or the editor. On behalf of the editors we hope that our authors and reviewers will continue to support the JAAA. Your editors will endeavor to continue to bring you high quality research papers in addition to Special Issues.

Gary P. Jacobson, Ph.D. Editor-in-Chief, Journal of the American Academy of Audiology 